\title{
BERNICE ZAMORA Y LORNA DEE CERVANTES: UNA ESTETICA FEMINISTA
}

\author{
POR \\ BRUCE-NOVOA \\ University of California, Santa Bárbara
}

Bernice Zamora y Lorna Dee Cervantes, poetas chicanas, son, a primera vista, muy distintas. Zamora es intelectual y académica; su poesía es abiertamente culta, con intertextualidades buscadas en autores como Shakespeare y Robinson Jeffers. La metáfora y la imagen predominan sobre la anécdota en su obra. Cervantes se cuida mucho de lo académico o lo intelectual; prefiere el mundo concreto de los objetos comunes, y sus referencias, aunque a veces a poetas cultos, suelen ser más al nivel de Carlos Castañeda —o sea, funciona a un nivel más coloquial que Zamora-. Destaca la anécdota sobre la metáfora en su poesía. Mientras Zamora ha cursado estudios graduados en Marquette y Stanford, Cervantes no quiso seguir estudiando después de high school. Zamora proviene de la cultura rural y conservadora de Nuevo México y el sur de Colorado; Cervantes, de un barrio urbano en San José, California. Difícil sería encontrar a dos poetas más diferentes.

Sin embargo, respecto a varias consideraciones fundamentales, Zamora y Cervantes no se distancian tanto. Me interesa aquí mostrar que ambas utilizan su primer libro para anunciar un tipo de ars poética y que, a pesar de las diferencias, el proceso y la dinámica del desarrollo de su posición respecto al mundo, la sociedad, a los hombres y la poesía, denuncian un paradigma similar. Finalmente, en los dos casos, la estética implícita tiene un carácter feminista.

Tanto Restless Serpents ${ }^{1}$, de Zamora, como Emplumada ${ }^{2}$, de Cervantes, comienzan con un poema sobre el sistema patriarcal, específicamente

${ }^{1}$ Bernice Zamora, Restless Serpents (Diseños Literarios, Menlo Park, 1976).

${ }^{2}$ Lorna Dee Cervantes, Emplumada (Pittsburgh: University of Pittsburgh Press, 1981). 
sobre un rito a través del cual los hombres tratan de estructurar la sociedad y la vida. Aunque ambas poetas muestran la eficacia del rito dentro de ciertos límites, ponen en tela de juicio su validez para con las mujeres. El texto en cada caso se va afirmando como otra posibilidad en oposición, una alternativa feminista no sólo porque se postula como algo diferente, sino porque se enfrenta al paradigma masculino como protesta, crítica y negación y porque encuentra sus raíces y fuerza en las mujeres mismas, a cuyas experiencias busca dar voz. Las dos asumen como punto de partida la situación marginada de la mujer, para luego invertirla y afirmarla como la virtud y el poder de otro centro. Y proponen el acto de escribir como una respuesta vital y un rito válido en contra de un sistema que las suprime. $O$ sea, ambas poetas postulan su existencia como un proceso dialéctico en que tienen que sobrepasar una definición de sí mismas como objeto del verbo exclusivamente reservado al sujeto masculino patriarcal. Para hacerlo tienen que apoderarse de los medios de articulación del proceso creativo y afirmar su derecho a su propio espacio de autodefinición. Convierten su libro en la producción y el producto de ese proceso - y, claro está, el productor también-. Veamos las obras para entender cómo realizan el proyecto.

El primer poema de Restless Serpents, "Penitents», evoca la tradición de la Hermandad de Penitentes, una organización religiosa y sociopolítica que mantuvo $-\mathrm{y}$ en algunos lugares sigue manteniendo- el orden en los pueblos del norte de Nuevo México y el sur de Colorado ${ }^{3}$. En el calendario ritual, las Pascuas Floridas era la fiesta más importante; Dios se sacrificaba por la humanidad. Su muerte y resurrección sirven de paradigma de todo sacrificio sagrado cristiano y aseguran tanto la continuidad en esta vida como la trascendencia del alma frente a la muerte. Los Penitentes conmemoran las Pascuas con un tipo de dramatización de la tortura y crucifixión de Cristo. Zamora evoca la ceremonia con todo su poder, horror sangriento y misterio. Los Hermanos centraban la sociedad al reunirse en la morada, tipo de iglesia sin cura que les servía de centro ritual, y el rito irradiaba un orden sagrado dentro del cual todo se ubicaba y se definía.

Cervantes no siente nostalgia por ningún orden sagrado, tal vez porque no vivió en ninguna zona rural donde la vieja fe se practicaba. Para ella, los ritos masculinos no son ni nobles ni conmemoran a ninguna figura gloriosa. En el primer poema de Emplumada, «Uncle's First Rabbit», evoca al hombre violento, el matón, el cazador. El rito es el del aprendizaje del niño que por primera vez tiene que salir a matar un conejo -tiene

3 Para más datos acerca de los Penitentes, consúltese Marta Weigle, The Pcnitentes of the Southwest (Santa Fe: Ancient City Press, 1970). 
que comprobar que es un hombre que puede matar para imponerse al mundo. Los hombres, nos dice Cervantes, practican el mismo modo de controlar su ambiente a lo largo de su vida, sobre todo respecto a las mujeres en casa o contra otras naciones en sus relaciones internacionales. E1 orden patriarcal es uno de imponer la voluntad a través de la violencia y muerte.

Tradicionalmente, ambos ritos son exclusivamente masculinos. Las mujeres no entraban a las moradas, como tampoco era su papel salir a cazar. De esta manera, estos ritos ordenaban la sociedad en divisiones absolutas: el nosotros masculino que actuaba y los otros que recibían los efectos de la acción y medían su valor según su relación al sujeto masculino. Las mujeres pasivamente sufrían los resultados. En «Penitents», la poeta recuerda que la ceremonia la atraía, pero como la morada le estaba vedada, tenía que irse hacia la naturaleza, asociándose a ella. Mientras los hombres buscaban relacionarse al mundo, a través de un rito violento realizado dentro de un edificio artificial y aislado de la naturaleza, la mujer fluye dentro del mundo en la naturaleza. Al estar al margen del rito masculino, la mujer se encuentra en el centro del mundo natural, que para el hombre es lo Otro. Cervantes también asocia a la mujer con la naturaleza a través de la identidad de víctima que comparte con los animales. El conejo, al morir bajo los golpes del niño, y la mujer, que llora por su bebé que ha muerto de los golpes de su propio padre, se unen metonímicamente con el verbo compartido to keen, lamentar con un chillido la muerte de algo o alguien. La naturaleza en Cervantes es lo otro violado por el hombre.

Para ambas, el orden patriarcal impone su identidad y supremacía a través de ritos violentos que dividen y aíslan los sexos. Sin embargo, al ser ubicada dentro de la naturaleza, la mujer se encuentra vinculada con lo otro, con la mayoría del mundo diferente al hombre. Ambas tomarán esa diferencia como seña de identidad y la convertirán en una subjetividad distinta a la del hombre, en una alternativa.

El primer paso en el proceso de diferenciación es el de ironizar el mismo rito masculino. Ambas afirman la eficacia del rito: los Penitentes logran producir un ambiente sagrado; los hombres de Cervantes aprenden a ser violentos para toda la vida. Sin embargo, la eficacia es irónica. En Cervantes, el rito produce la muerte, el sufrimiento, el temor y el odio; el mismo hombre denuncia su enajenación al llamar a su padre un bastardo y al querer escapar del espacio ritual. Este orden es siniestro en su eficacia porque oprime a todos.

Zamora es más compleja y sutil. Primero crea un tono nostálgico en que el rito parece perderse en un pasado inalcanzable. Lo logra a través 
del uso de verbos en tiempo pasado cuando habla de su relación al rito, que a su vez se había presentado en tiempo presente. La poeta queda fuera del círculo mitológico, o sea, sagrado, del rito. Además, como he mostrado en otro lugar (1982: 165), este distanciamiento ocurre en el momento en que el poema debiera enfocarse en la crucifixión, el punto culminante del rito. De esta manera, la poeta desplaza la atención, los ojos mismos, de los lectores hacia ella misma en el momento más intenso en que la humanidad y el mundo se unen a través del sacrificio. Ese sacrificio resulta ser el de ella y del mundo. De repente vemos «crater lakes and desecrated groves», la naturaleza violada, que a la vez sobrevive en espacios sagrados, y a la poeta que fluye en las aguas del mundo. Todo el rito masculino del poema revela una preparación para otro más vasto y permanente, el de la naturaleza femenina.

También Zamora ha invadido al ritmo mismo, anticipando la revelación final. En la estrofa central del poema, cuando los Penitentes se autoflagelan, Zamora introduce imágenes femeninas. Los látigos son «Rosary whips», una alusión al rosario que se reza en nombre de la Virgen María, madre de Cristo. Además, en el verso central del poema la poeta esconde la imagen de la víbora dentro de la columna vertebral de los Penitentes: «Hissing spine to uncoil wailing tongues» (p. 8). La víbora, tradicionalmente una imagen bisexual o andrógina, es, como ha notado recientemente la profesora Juanita Lawhn, también una representación de la diosa Afrodita cuando se esconde en la columna vertebral. Así es que Zamora implícitamente acusa a los Penitentes de deseos sexuales suprimidos que se frustran aún más como resultado del rito que los aíslan de la mujer. Podemos o no estar de acuerdo con el uso que Zamora hace de imágenes y arquetipos masculinos y femeninos, pero lo importante aquí es que los utiliza para trascender las divisiones patriarcales e invadir el ritmo masculino, apoderándose, aunque ahora sólo veladamente, de su centro. Afrodita y la Virgen María - tal vez sean la misma imagen a fin de cuentasdesplazan a Cristo, como la poeta lo hace en la estrofa culminante.

El segundo paso de distanciamiento y diferenciación es la autodefinición no sólo de marginadas, sino de sobrevivientes de la opresión. «Penitents» ya tiene algo de eso en su tono nostálgico. Mas en «Pueblo, 1950», Zamora recuerda cuando un joven la besó y la vergüenza que sintió porque todo el mundo la hizo sentirse la culpable, aunque nadie dijera nada al muchacho. Este acto aparentemente inocente es, no obstante, una violación sexual incipiente, y en Cervantes, siempre más directa, estalla plenamente. «Lots I» y «Lots II» tratan abiertamente una violación sexual en toda su brutalidad.

En ambos casos, la mujer violada se encuentra no sólo la víctima del 
hombre, sino de su circunstancia y de las mujeres que no la apoyan. Los agentes de la culpabilidad, las voces que imponen el orden masculino, en «Pueblo, 1950» son las mujeres. Zamora no tenía ningún refugio con ellas. Cervantes dice «I made a list in my head / of all the names who could help me / and then meticulously I scratched / each one / they won't hear me burning / inside of myself» (p. 12). Las dos mujeres han pasado por un tipo de rito de iniciación en que personalmente han entrado al grupo de las víctimas violadas. En cada caso el rito sigue el modelo del primer poema de su respectivo texto. El hombre impone su orden: en Zamora, por un acto aparentemente inocente con aire de juvenil juego de antaño; en Cervantes, el violador aplica la lección de pegar a su víctima hasta que se rinda o se muera.

$\mathrm{Al}$ repetir la misma estructura de opresión patriarcal en un nivel personal, cada poeta tiene también que repetir la ironización y el rechazo en este mismo nivel. Y además de distanciarse del hombre, marcarán su diferencia con respecto a las mujeres tradicionales que aceptaban el orden patriarcal como un absoluto ineluctable. El acto fundamental del distanciamiento es el de no quedarse callada. El silencio es la complicidad, y Zamora denuncia no sólo al hombre culpable, nombrándolo en el texto, sino al sistema mismo que le impuso su ingenua complicidad y silencio. Cervantes declara: «She would not be / silent and still» (p. 11). El hecho de dar voz a la protesta es clave, porque de esta manera la dialéctica de sujeto sobre objeto se torna en el enfrentamiento de sujeto contra otro sujeto. $Y$ es la poesía misma, el texto, donde esa voz se expresa y se hace oír. La poesía se convierte en el espacio de la lucha y de afirmación feminista.

Del acto de sobrevivir, la poeta tiene que tomar fuerza. Zamora lo hace con el mero hecho de poder ahora pronunciar el nombre del violador. En otros poemas, como «From the Vestibule» y «Among the Ordained», son los que han sido excluidos de la iglesia los que entienden mejor el sentido de lo sagrado - y Zamora nota que, aun cuando estaban adentro, las mujeres sólo participaban en el coro-. Pero esa perspectiva es la más correcta. De la opresión y la marginalización, dice, surge la sabiduría, en sí un centro nuevo. Cervantes utiliza la intertextualidad para convertir la violación en otro tipo de rito de iniciación. "Lots I», cuyo subtítulo es "The Ally», termina: "She would live / arrogantly, / having wrestled / her death / and won» (p. 8). Las alusiones son a Carlos Castañeda y a su concepto del aliado, que Cervantes ha utilizado como epígrafe para la primera sección de su libro. «Consider the power of restling your ally. His 'will is to kill you. He has nothing against you» (p. 1). Según Castañeda, si uno derrota al enemigo, lo convierte en un aliado 
(ninguna sorpresa para cualquier estudiante de mitología). Este rito dota a los que vencen de una fuerza nueva: la de conocerse a sí mismos y de confiar de su propia capacidad de sobrevivir cualquier cosa. En "Lots II", que se subtitula «Herself», la poeta ya no necesita que nadie la defienda; sabe que ella lo puede hacer.

Se presenta, sin embargo, otra amenaza: el peligro de que esa nueva voz de protesta y afirmación se convierta en un remedo de la voz masculina, la voz de la opresión. Zamora y Cervantes, al postular un principio en el reconocimiento de la necesidad de rechazar el paradigma patriarcal, implícitamente enuncian el dilema que cientos de feministas han documentado: la tradición literaria más visible es un código masculino del cual las mujeres han sido eliminadas. Aún más, ese código, como parte del texto social en general, afirma el orden patriarcal. La mujer rechaza ese sistema, pero a la vez reconoce la imposibilidad de prescindir de él del todo. Por lo menos es un punto de partida para buscar algo más auténtico. Zamora y Cervantes admiten su relación estrecha con ese código masculino de la poesía, pero lo matizan, cada una a su modo, apropiándolo para sus necesidades.

Zamora confronta a los poetas que más la atraen a través de una serie de parodias correctivas, como expliqué en Chicano Poetry ${ }^{4}$ (pp. 160-184). De esta manera declara sus influencias a la vez que se diferencia de ellas: de nuevo el rito dialéctico. A Robinson Jeffers, el gurú de la inhumación y lo irracional, Zamora brinda algunos de sus mejores poemas. Pero humaniza la temática de Jeffers en una refutación de sus teorías. Combina material sacado de la poesía de Jeffers para producir resultados totalmente opuestos. Mientras Jeffers descentraliza y degrada a la humanidad y su capacidad razonal, Zamora las centraliza como el origen del bien. Además, Zamora rescata a las mujeres pasivas y marginadas de Jeffers para convertirlas en activas y centrales. Toma un poema de Theodore Roethke, en que el hombre explora la naturaleza solo en su camioneta, y lo escribe de nuevo, poniéndose a sí misma en el vehículo. Parodia el Soneto CXVI de Shakespeare para declarar su antipatía por los machos y sus juegos violentos y destructivos y afirmar una preferencia por los homosexuales. En cada caso la parodia ajusta la imagen del escritor y su obra, matizándolos y prestándoles un aire más justo, más humano y, por ende, supuestamente menos patriarcal.

${ }^{4}$ Bruce-Novoa, Chicano Poetry: A Response to Chaos (Austin, Texas: University of Texas Press, 1982). También Chicano Authors: Inquiry by Interview (Austin, Texas: University of Texas Press, 1980). 
Cervantes hace algo parecido. Admite que sus lecturas eran de hombres; aún más, que la literatura y el código masculino eran sinónimos: «I turned to books, those staunch, upright men» (p. 11). Un hombre le enseño «to read all those windsongs / in the verses of Stevenson» (p. 15). Sin embargo, también utiliza la ironía. A los «staunch, upright men» de los libros yuxtapone en el mismo poema la realidad de hombres borrachos e irresponsables que tratan de matar a las mujeres. Cuando un hombre invade la casa, es un ser inhumano: «it entered the house in hard / unsteady steps» (p. 13). La poeta siempre tiene que cerrar con llave la puerta de su recámara para protegerse del padrastro. Cuando se refiere a los poetas románticos, entre los cuales sí incluye a una mujer, los enmarca entre imágenes del amor sacadas de su vida mucho menos ideal. «They 'were such / dumb hunks of warm fish / swimming inside us / but this was love... I read / you the poems of Lord Byron, Donne, / the Brownings: all about love, / explaining the words / before realizing that you knew / all that the kicks in your belly / had to teach you» (pp. 16-17). Y su mentor, Edward Long, es la figura misma de un ser marginado: un borracho sin casa a quien el estado interna en un manicomio. $O$ sea, en el caso de Cervantes la poesía masculina representa un ideal contrapuesto a la realidad y a la vez una tradición marginada por los mismos hombres. El mundo controlado por los hombres no es ni lírico ni amoroso. Pero la poesía brinda otra alternativa. Cervantes no puede seguir el modelo patriarcal en su temática a ciegas, pero sí aprende la lección de la literatura como un espacio alternativo, o como se diría en otros círculos, la lección de la acción simbólica.

A esa tradición literaria patriarcal ambas poetas agregan el conocimiento femenino o andrógino. En «Bearded Lady» (p. 14), Zamora atribuye a ese ser andrógino el conocimiento del amor. Aunque la señora barbuda no ofrece una definición clara del amor, sí presenta una imagen rotunda: se acaricia su barba, pasando la mano sobre ella una y otra vez. Esta imagen hermafrodita también puede interpretarse como el apoderarse, por parte de la mujer, del símbolo masculino de la sabiduría, del poder y de la fuerza sexual. Es a la vez una masturbación, y las posibilidades netamente lesbianas tampoco se deben descartar. $\mathrm{Y}$ como el amor armónico es una de las metas del libro de Zamora, esta imagen es una clave: en un ser las fuerzas opuestas llegan a fundirse. Pero Zamora. aprende más de las mujeres en la literatura, aunque sean personajes de escritores. Es una lección de frustraciones, manipulaciones y silencios impuestos a los cuales Zamora da voz.

Cervantes es más directa. Aprende de su amiga escolar, golpeada y amenazada por el padre de su hijo, que la vida patriarcal no es nada 
ideal. También aprende de las señoras del barrio, que la aconsejan que aprenda cosas prácticas: «Know good polished oak. / Learn hammer and Phillips. / Learn socket and rivet» (p. 19). Pero es de las mujeres de su familia de las que aprende más. "You're too soft... always were. / You'11 get nothing but shit. / Baby, don't count on nobody» (p. 13), le aconsejaba la madre. Pero ya en el poema se había dicho que la madre había asumido el rol del hombre en la familia de puras mujeres, así es que podríamos desconfiar de sus palabras. La abuela se nos ofrece como el modelo femenino de más confianza. De ella la poeta aprende una actitud también de cierta desconfianza para con los hombres, pero a la vez más abierta al mundo. Le enseña a leer el texto de la naturaleza, a interpretar a los pájaros, que han logrado desarrollar una manera de vivir más auténtica. «Mockingbirds sing all night. / Grandma says they are singing for their nesting 'wives. / They don't leave their families / borrachando... / She believes in myths and birds. / She trusts only what she builds / with her own hands» (p. 12). También aprende, implícitamente, la lección de sobrevivir y convertir la experiencia -mala o buena- en algo útil, positivo. Según la madre, el abuelo trató de matar a la abuela, pero luego ésta hace mantas de los trajes del señor. Cervantes incorpora el mensaje y el ejemplo de la abuela: es más abierta, más sensible y más suave que su madre, y cuando madura, duerme con un hombre gentil. Sin embargo, no descarta del todo el consejo de la madre: sigue un tanto desconfiada, siempre guardando un poco de su intimidad para sí. Sobre todo se asocia con los pájaros - su poesía está repleta de imágenes de pájaros y la poeta se autodenomina emplumada - y sólo confía en lo que ella misma hace con sus manos. Crea una síntesis de la sabiduría femenina de su tradición inmediata.

Ambas poetas afirman, a fin de cuentas, la necesidad de escribir, de encontrar una voz y romper el silencio tradicional. Esa voz tiene que distanciarse y diferenciarse de la de los hombres. La poesía, en ambos casos, les ofrece otra posibilidad de expresarse, pero también tienen que cambiar la poesía para que sea un rito no patriarcal, que sea el espacio de oposición y creación. Zamora hace de su poesía el espacio de encuentros entre hombres y mujeres; busca una colaboración entre iguales en vez de la separación y subordinación sexuales. Cuando no logra el ideal, toma el poder para celebrar un rito nuevo, el de escribir poesía sobre y para su gente, sobre todo para las chicanas. Al final, ese rito es de la mujer solitaria, aislada del hombre, sirvienta de los impulsos sexuales y sociales a que trata de dominar a través de la poesía. En el último poema de su texto, «Restless Serpents», las víboras que en el primer poema se escondían atrapadas en la imagen de la columna vertebral, están libres para 
imponer una ceremonia más abiertamente rebelde en que la poeta les dará lo que piden: la devastación de todo.

Cervantes convierte su poesía en la afirmación del amor y la creatividad en armonía con la naturaleza. Durante su aprendizaje se le enfrentan muchos enemigos que la asaltan, que de algún modo tratan de matarla, y que son avatares del mismo enemigo/aliado. Su mamá la guiaría a ser dura, odiosa y negativa. Un joven burgués le hace reaccionar violentamente en un remedo de los hombres y su sistema de imponerse a través de la muerte, y en ese poema sus versos son un remedo de los clichés de de la poesía política más fácil y choteada, otra forma de muerte para una poeta. Sin embargo, Cervantes sobrevive cada vez, utiliza las lecciones y se va haciendo más fuerte y sabia. Al final nos ofrece el texto mismo como prueba de su éxito.

Ambos libros son feministas en su proceso y estructura. Dialécticamente se enfrentan al sistema patriarcal y se declaran en oposición, se declaran lo Otro, pero ya como sujeto de su propio discurso, diferenciado, aunque siempre en relación a ese polo masculino. Piden una síntesis de las fuerzas vitales, pero sólo si es la síntesis equilibrada y justa. Y saben que esa síntesis será posible únicamente cuando los dos polos se encuentren como iguales; o sea, reconocen la necesidad de lograr la libertad de acción y de autocreación que tanto tiempo les ha sido negado. Y feministas porque, aunque sean textos chicanos, la problemática esencial no es étnica, sino sexual. Aunque sean muy distintas, Zamora y Cervantes comparten una conciencia feminista. 
